\title{
Introduction to the Second Half of the Meeting
}

\author{
Ted Hutchin, Engineering Industry Training Board, East Midlands
}

The final two sessions of the afternoon will present a change of emphasis away from further education and higher education. We will now be looking at two slightly different aspects; the first is the effect of information technology (IT) training in schools and the other is the industrial implications. These two are linked together for a very real reason, which is that many people leave school and go straight into industry whether this be commercially-based industry or the manufacturing industry. As a result of that switch they are expected to use IT rather than learn more about it. We then move into the area where potential users have not yet got into IT or that of actual users who also need to be trained. These throw up a whole series of different problems from those that we have already heard. Concerning the kind of courses that we run in the Training Board, one of the main reasons for being asked to run such courses is to reduce anxiety and fear about the uses of IT and how it is going to affect those involved. This involvement of the user, the training and some aspects of decision making are seen as being quite crucial, certainly in the Training Board. What we are finding is that there are an increasing number of barriers to the use of IT, not the least being created by IT specialists themselves. This results from the jargon and terminology that they tend to use, and indeed some of them love to use, which baffles the person who is going to buy and use it. In summary, we are now going to look very much at the users of IT. 